\title{
Community acquired lobar pneumonia in patients with HIV infection and AIDS
}

\author{
Robert F Miller, Noeleen M Foley, David Kessel, Andrew A Jeffrey
}

\begin{abstract}
Background - Community acquired bacterial pneumonia is increasingly encountered in HIV infected individuals and some patients have a radiographic lobar pneumonia.

Methods - A retrospective review of clinical features, microbiological diagnosis, and outcome of community acquired lobar pneumonia was carried out in HIV positive patients admitted to a specialist unit from 1987 to 1993.

Results - Forty nine episodes occurred in 45 patients, all of whom were men. CD4 counts ranged widely. A bacteriological diagnosis was made in 25 episodes (51\%), seven patients had more than one infective cause. The commonest pathogens were Streptococcus pneumoniae (11 episodes), Staphylococcus aureus (six), Pneumocystis carinii (three), Haemophilus influenzae (three), and Pseudomonas aeruginosa (two). Four patients died. Other complications included intrapulmonary cavitation or abscess formation (11 episodes), empyema (three), and pleural effusion (10 episodes).

Conclusions - Many different infections cause community acquired lobar pneumonia in HIV positive men. Some patients have coinfections and there is a high complication rate.
\end{abstract}

(Thorax 1994;49:367-368)

Although Pneumocystis carinii pneumonia remains the commonest cause of respiratory disease in HIV positive patients, bacterial infections are increasingly encountered. In this study we report the clinical features, microbiological diagnoses, and outcome of community acquired lobar pneumonia in HIV antibody positive men.

\section{Methods}

Consecutive HIV antibody positive men admitted to a dedicated inpatient unit for respiratory investigations from 1987 to June 1993 were studied and those with community acquired radiographic lobar pneumonia identified (patients had not been inpatients for 30 or more days before this admission).

From each patient's records we obtained the following data: (1) age, risk factors for HIV infection, duration and previous manifestations of HIV disease, smoking history, and the presence of underlying general medical conditions; (2) type and use of pneumocystis prophylaxis, zidovudine and glucocorticoids; (3) symptoms and signs; (4) blood urea levels, arterial oxygen tension, peripheral blood white cell count, CD4 lymphocyte count (CD4 lymphocyte counting became available in mid 1991 and was available in 26 patients) on admission; (5) bacteriological diagnosis obtained by microbiological and cytological examination of spontaneously expectorated sputum, induced sputum or bronchoalveolar lavage fluid and culture of blood, and the results of atypical respiratory serology; (6) clinical outcome including complications and death. Chest radiographs were reviewed (by DK who was blind to the clinical diagnosis); the site and extent of lobar involvement and the presence of effusion and abscess or cavity formation was noted.

\section{Results}

Fifty three episodes of community acquired lobar pneumonia occurred in 49 patients; patient records were incomplete in four episodes. We report here the results of 49 episodes in 45 patients. During this period 523 patients were admitted to the unit with respiratory episodes.

All the patients were men of mean age 36.7 (range 23-64) years; 43 were homosexual, two were bisexual. None used intravenous drugs. Thirty were cigarette smokers and three were ex-smokers. None had diabetes mellitus nor heart disease and none was receiving glucocorticoids.

In two episodes of pneumonia HIV infection was diagnosed concurrently, and in the remaining 47 episodes patients had been HIV antibody positive for between one and 108 (median 36) months. Twenty three patients had prior AIDS diagnoses including pneumocystis pneumonia in 17 .

In 12 episodes patients were taking zidovudine and antipneumocystis prophylaxis, nine were taking prophylaxis but not taking zidovudine, eight were taking zidovudine but not prophylaxis, and the remaining patients were taking neither zidovudine nor prophylaxis.

All patients had fever, cough and dyspnoea; 29 had sputum expectoration (one had haemoptysis) and 25 had pleural pain. None with 
Table 1 Bacterial diagnosis and patient characteristics in 49 episodes of community acquired lobar pneumonia in 45 HIV positive patients

\begin{tabular}{|c|c|c|c|c|}
\hline Organism & $n$ & $\begin{array}{l}\text { Range (mean) } \\
\text { CD4 count }\left(\times 10^{9} / l\right)^{*}\end{array}$ & $\begin{array}{l}\text { Range [mean] WBC }\left(\times 10^{9} / l\right) \\
\text { total (neutrophils) }\end{array}$ & $\begin{array}{l}\text { Range (mean) } \\
\mathrm{PaO}_{2}(\mathrm{kPa})\end{array}$ \\
\hline $\begin{array}{l}\text { Streptococcus pneumoniae } \\
1 \text { also had Staphylococcus epidermidis } \\
1 \text { also had Haemophilus influenzae } \\
\text { and Staphylococcus aureus }\end{array}$ & 11 & $0.01-0.14(0.07)$ & $\begin{array}{l}3.9(1.6)-26.5(23.9) \\
{[8.8(7.2)]}\end{array}$ & $7 \cdot 7-13 \cdot 4(10 \cdot 1)$ \\
\hline $\begin{array}{l}\text { Staphylococcus aureus } \\
1 \text { also had Pneumocystis carinii } \\
1 \text { also had group A Streptococcus }\end{array}$ & 5 & $0.04-0.08(0.03)$ & $\begin{array}{l}4 \cdot 2(3 \cdot 8)-16 \cdot 5(15 \cdot 5) \\
{[8 \cdot 2(6 \cdot 9)]}\end{array}$ & $7 \cdot 9-11 \cdot 4(9 \cdot 8)$ \\
\hline Pseudomonas aeruginosa & 2 & $0.01-0.03(0.02)$ & $\begin{array}{l}1 \cdot 4(1 \cdot 1)-20(19 \cdot 2) \\
{[7 \cdot 6(7 \cdot 1)]}\end{array}$ & $10.6-16.5(13.5)$ \\
\hline $\begin{array}{l}\text { Pneumocystis carinii } \\
1 \text { also had Enterobacter cloacae }\end{array}$ & 2 & $0.01-0.18(0.09)$ & $\begin{array}{l}2 \cdot 4(2 \cdot 0)-5 \cdot 6(4 \cdot 3) \\
{[4 \cdot 1(3 \cdot 1)]}\end{array}$ & $11 \cdot 4-13 \cdot 2(12 \cdot 4)$ \\
\hline $\begin{array}{l}\text { Haemophilus influenzae } \\
1 \text { also had Salmonella typhimurium } \\
1 \text { also had Mycobacterium avium-intracellulare }\end{array}$ & 2 & ND & $3.8(1.9)-5.8(4.7)$ & $8 \cdot 9-10 \cdot 9$ \\
\hline $\begin{array}{l}\text { Fusobacterium nucleatum } \\
\text { Salmonella cholera-suis } \\
\text { Mycobacterium tuberculosis }\end{array}$ & $\begin{array}{l}1 \\
1 \\
1\end{array}$ & $\begin{array}{l}0 \cdot 47 \\
\text { ND } \\
0 \cdot 10\end{array}$ & $\begin{aligned} 10 \cdot 2(9 \cdot 6) \\
8 \cdot 2(6 \cdot 8) \\
6 \cdot 9(5 \cdot 3)\end{aligned}$ & $\begin{array}{l}5 \cdot 9 \\
\text { ND } \\
9 \cdot 1\end{array}$ \\
\hline No organism identified & 24 & $0.01-0.78(0.28)$ & $\begin{array}{l}2 \cdot 4(2 \cdot 1)-44 \cdot 7(38 \cdot 7) \\
{[10 \cdot 0(8 \cdot 3)]}\end{array}$ & $7 \cdot 4-16 \cdot 0(10 \cdot 8)$ \\
\hline
\end{tabular}

$\mathrm{ND}=$ not done. ${ }^{*}$ Normal range $=0.35-2.2 \times 10^{9} / 1$

pneumocystis pneumonia had pleural pain. The magnitude of fever and the presence of sputum did not distinguish between causes.

A microbiological diagnosis was made in 25 episodes (51\%) (table 1 ). Paired atypical serological results were available in 26 episodes and were non-contributory. Nine of those with negative cultures and three with positive cultures were taking antibiotics at the time of admission. Sputum or bronchoalveolar lavage was positive in six with Streptococcus pneumoniae, five with Staphylococcus aureus, three with Haemophilus influenzae and those with Streptococcus group A, Enterobacter cloacae, Mycobacterium avium-intracellulare, and $M$ tuberculosis (stool and urine also positive). Blood cultures were positive in six with Str pneumoniae, both with Pseudomonas aeruginosa, both with salmonella infections, one with Staph aureus, and those with Staph epidermidis and Fusobacterium nucleatum. Arterial oxygen tensions and peripheral blood white cell counts did not discriminate between infective causes (table 1). No patient with pneumocystis pneumonia had an elevated white count. The number and site of lobes involved radiographically varied widely. Consolidation was lobar in 20 instances and segmental in 29. In 39 episodes the radiographic abnormality was unilateral (24 right sided), and in 10 it was bilateral. Upper lobes were involved in nine instances, lower lobes in 36 , and the middle lobe in 15 . In 11 instances interstitial shadowing was present in other lobes. Neither the radiological site, the extent of pneumonia, nor the presence of interstitial shadowing enabled discrimination between infective causes to be made.

Four patients died. The first was confused, hypoxaemic, uraemic, and had right upper and middle lobe pneumonia on admission. Sputum and blood grew Str pneumoniae, and intrapulmonary abscess formation and empyema occurred. Two patients with $P$ s aeruginosa pneumonia were bacteraemic; one was hypotensive, and had left upper and middle lobe pneumonia, and the other was uraemic with a leucocytosis and an empyema; both had cavitation. The fourth patient had $M$ avium-intracellulare and $H$ influenzae infections; intrapulmonary cavitation occurred. Of the other patients, two with Str pneumoniae had cavitation and pleural effusions and one also had empyema. Two patients with Staph aureus (including one who also had pneumocystis pneumonia), and two with pneumocystis pneumonia (including one who had Ent cloacae coinfection) also had cavitation. The patients with $F$ nucleatum and $M$ tuberculosis infections had effusion. Of those with negative investigations six had pleural effusion and one had intrapulmonary cavitation.

\section{Discussion}

In this study community acquired lobar pneumonia was caused by a wide variety of organisms and occurred throughout the course of HIV disease. As has previously been reported, Str pneumoniae was the commonest cause, with the second most common infection being Staph aureus.

Not all patients had a peripheral blood leucocytosis so we were unable to use the white blood cell count to discriminate between causes. Similarly, arterial oxygen tensions varied widely and did not provide discriminatory information. In our study 13 of the 30 bacterial isolates were identified in blood; no correlation between the stage of disease or CD4 count and the presence of bacteraemia was identified.

A high rate of complications was noted in our patients, particularly intrapulmonary cavitation and abscess formation. An explanation for this is not immediately apparent. All four patients who died had three or more features associated with an increased risk of death in the general population with community acquired pneumonia. ${ }^{2}$ This suggests that the same predictive indices are applicable to HIV positive patients with lobar pneumonia.

1 Magnenat J-L, Nicod LP, Auckenthaler R, Junod AF. Mode of presentation and diagnosis of bacterial pneumonia in human immunodeficiency virus infected patients. Am Rev Respir Dis 1991;144:917-22.

2 British Thoracic Society: Pneumonia Subcommittee. Guidelines for the management of community-acquired pneumonia in adults admitted to hospital. Br $\mathcal{F}$ Hosp Med 1993;49:346-50. 